\title{
Prediksi Crash Saham Menggunakan Log Periodic Power Law dengan Nonlinear Optimization (Studi Kasus: Pasar Saham Indonesia)
}

\author{
Ditta Febriany Sutrisna ${ }^{1}$, Jondri ${ }^{2}$, Aniq Atiqi Rohmawati ${ }^{3}$ \\ Prodi Ilmu Komputasi, Fakultas Informatika, Universitas Telkom \\ 1'dittafebriany@gmail.com \\ 2jondri@telkomuniversity.ac.id \\ 3 aniqatiqi@telkomuniversity.ac.id
}

\begin{abstract}
The movement of stock price index become a benchmark for investors to make decisions which will be taken to sell, to hold, or to buy the stock. Therefore, the condition of stock price are uncertain, hence the financial markets are prone to crash the stock price. This research is using the model of the Log Periodic Power Law with Nonlinear Optimization to predict the crash of the stock price. Nonlinear Optimization has two steps, they are Tabu Search method and algorithm Levenberg-Marquardt nonlinear least squares. The purpose of Tabu Search method is to get the initial values of the model parameters LPPL, and the algorithm Levenberg-Marquardt nonlinear least squares is to get parameters value of the model LPPL. The result of stock crash prediction can be seen from the distribution of the estimated critical time with the greatest opportunities. Based on information from data IHSG, crisis occured in October 2008. The result of prediction is using the model of the LPPL with Nonlinear Optimization indicates time a value of stock price crashes is nearly on the date Januari $23^{\text {th }} 2008$. The expected value with the highest time probability is January 31 st 2008.
\end{abstract}

Keywords: Crash, Log Periodic Power Law, Tabu Search, Levenberg-Marquardt

\section{Abstrak}

Pergerakan indeks harga saham menjadi tolak ukur para investor untuk membuat keputusan yang akan diambil seperti menjual, mempertahankan, atau membeli saham tersebut.Akan tetapi kondisi harga saham yang tidak menentu atau naik turun, mengakibatkan pasar keuangan rentan terhadap crash harga saham. Pada penelitian ini, digunakan model Log Periodic Power Law dengan Nonlinear Optimization untuk memprediksi crash terhadap harga saham. Nonlinear Optimization terdapat dua tahap yaitu metode Tabu Search dan algoritma Levenberg-Marquardt kuadrat terkecil nonlinier. Metode Tabu Search untuk mendapatkan tebakan awal dari parameter model LPPL, dan algoritma LevenbergMarquardt kuadrat terkecil nonlinier untuk mendapatkan nilai parameter dari model LPPL. Hasil prediksi crash saham dilihat dari distribusi perkiraan waktu krisis dengan peluang paling besar. Berdasarkan informasi dari data IHSG, krisis terjadi pada bulan Oktober 2008. Hasil prediksi menggunakan model LPPL dengan Nonlinear Optimization menunjukkan waktu crash harga saham mendekati nilai pada tanggal 23 Januari 2008. Nilai harapan dengan probabilitas waktu paling besar terjadi pada tanggal 31 Januari 2008.

Kata Kunci: Crash, Log Periodic Power Law, Tabu Search, Levenberg-Marquardt 


\section{Pendahuluan}

K RISIS pada pasar keuangan merupakan salah satu dampak terjadinya krisis ekonomi. Penurunan harga secara tiba-tiba dan dramatis terhadap indeks harga saham dalam waktu yang singkat, sehingga besar penurunan harga saham yang negatif berdampak buruk bagi pasar dan mengakibatkan kerugian yang besar disebut sebuah crashpada pasar keuangan[1]. Dari sudut pandang lain, crash adalah efek informasi negatif yang terdapat dalam perdagangan harga untuk jangka waktu yang singkat dan hampir tidak mungkin untuk memprediksikan besar atau waktu terjadinya krisis [2]. Crash harga saham yang tinggi, membuat harga saham terus menurun dan mengakibatkan kegiatan ekonomi terganggu. Crash yang terjadi pada pasar saham mengakibatkan penurunan harga saham selama beberapa bulan atau tahun, namun tidak berlangsung selamanya. Adanya ketidakpastian terjadinya crash harga saham, diperlukan pemodelan untuk memprediksi terjadinya crash harga saham. Hasil prediksi ini digunakan untuk membantu para investor saham dalam mengambil keputusan.

Log Periodic Power Law (LPPL) merupakan salah satu model yang digunakan untuk memprediksi harga saham sebelum dan selama terjadinya crash terhadap pasar keuangan secara keseluruhan [3]. Persamaan dari model tersebut merupakan penggabungan dari Log Periodic dan Power Law. Untuk menguji model yang telah di dapat, penulis menggunakan data histori harga saham sebelum terjadinya krisis dan sesudah terjadinya krisis. Penelitian selanjutnya mengukur tingkat performansi dari Log Periodic Power Law studi kasus pasar saham Indonesia.

Model Log Periodic Power Law pernah digunakan dalam penelitian sebelumnya yaitu memprediksi crash harga saham yang populer pada Oktober 1987 dan pasar Brazilian, Cajueiro, Tabak dan Werneck (2009) telah berhasil menerapkan model untuk memprediksi perilaku bencana dengan seri harga dari 21 saham [2].

Berdasarkan penjelasan singkat diatas, penulis melakukan penelitian untuk memprediksi crash harga saham dengan menggunakan model Log Periodic Power Law dengan Nonlinear Optimization. Nonlinear Optimizationterdapat 2 tahap dalam fitting model LPPL yaitu menggunakan metode Tabu Search dan algoritma Levenberg-Marquardtkuadrat terkecil nonlinier [3] dengan studi kasus pasar saham di Indonesia.

\section{LANDASAN TEORI}

\section{A. Gelembung}

Menurut Kindleberger, definisi gelembung dapat diterima secara luas [4]: "gelembung dapat didefinisikan sebagai peningkatan yang tajam terhadap harga aset... dalam suatu proses yang berkesinambungan, dengan awal yang menghasilkan harapan kenaikan lebih lanjut dan menarik pembeli baru - umumnya para investor tertarik pada keuntungan perdagangan aset daripada penghasilan. Biasanya peningkatan diikuti oleh pembalikan harapan dan penurunan harga yang tajam sehingga menyebabkan terjadinya krisis keuangan".

Pada pasar modal, pasti terdapat gelembung (bubble) saham, dimana harga saham tidak dapat menggambarkan kinerja perusahaan secara keseluruhan. Gelembung ekonomi terbentuk ketika harga saham melambung jauh diatas nilai fundamentalnya atau melebihi harga sebenarnya. Hassett (2002) mendefinisikan financial bubble yaitu sebuah periode dimana harga sebuah aset tiba-tiba meningkat tajam untuk alasan yang tidak rasional dan kemudian drop tajam [5].

\section{B. Model Log Periodic Power Low}

Log Periodic Power Law (LPPL) merupakan model yang dikemukakan oleh Johansen dan Sornette. Model LPPL mengidentifikasi harga saham sebelum dan selama terjadinya crash di pasar modal. Model LPPL digunakan untuk mengamati perubahan yang terjadi pada harga saham sebelum terjadinya crash [3]. Bentuk persamaan dari LPPL [1][3].

$$
y_{t}=A+B\left(t_{c}-t\right)^{\beta}\left(1+C \cos \left(\omega \ln \left(t_{c}-t\right)^{\beta}+\phi\right)\right)
$$

Keterangan : 
$y_{t}$ : adalah harga (indeks), atau log dari harga, pada waktu $; y_{t}>0$

A : adalah nilai $\mathrm{y}(\mathrm{t})$ pada saat kritis; $\mathrm{A}>0$

$\mathrm{B}$ : adalah penurunan $y_{t}$ selama satuan waktu sebelum kecelakaan; $\mathrm{B}<0$

$\mathrm{C}$ : adalah besarnya proporsional fluktuasi sekitar pertumbuhan eksponensial; $|\mathrm{C}|<1, \mathrm{C} \neq 0$.

$\mathrm{t}_{\mathrm{c}}>0$ : adalah waktu terjadi crash / kecelakaan

$\mathrm{t}<\mathrm{t}_{\mathrm{c}}$ : adalah setiap waktu dalam bubble sebelum terjadinya $\mathrm{crash} ; \mathrm{t}_{\mathrm{c}}$

$\beta$ : adalah eksponen dari power law growth; $0 \leq \beta \leq 1$

$\omega$ : adalah frekuensi dari fluktuasi selama gelembung (bubble); $0 \leq \omega \leq \infty$

$\phi$ : adalah parameter pergeseran; $0 \leq \phi \leq 2 \pi$

\section{Metode Tabu Search}

Tabu Search adalah sebuah metode optimasi yang berbasis pada local search. Tabu Search merupakan metode heuristik yang umumnya digunakan untuk menemukan solusi seakurat mungkin yang mendekati optimal dari sebuah masalah dengan jalan melakukan move. Move yang dimaksud adalah proses pencarian bergerak dari satu solusi ke solusi berikutnya. Tabu Search memperbaiki performansi pencarian lokal dengan memanfaatkan penggunaan struktur memori. Strukur memori fundamental tersebut dinamakan Tabu List. Tabu List menyimpan solusi-solusi optimal yang telah ditemukan pada iterasi sebelumnya. Tabu List juga digunakan untuk menuntun proses pencarian agar menelusuri solusi-solusi yang belum pernah dikunjungi sehingga tidak terjadinya perulangan [6].

Skema umum metode Tabu Search, yaitu [7] :

1. Menentukan sebuah solusi awal saat ini.

2. Membuat sebuah daftar tabu untuk semua calon solusi.

3. Evaluasi setiap kandidat solusi dan pilih kandidat terbaik (penerimaan kandidat didasarkan padapembatasan tabu\& kondisi aspirasi).

4. Jika kondisi berhenti terpenuhi, maka didapatkan solusi akhir.

5. Jika tidak, perbaharui kondisi-kondisi penerimaan pada pembatasan tabu\& kondisi aspirasi.

6. Kembali ke langkah 2.

\section{Algoritma Levenberg-Marquardt Kuadrat Terkecil Nonlinier}

Metode Levenberg-Marquardt merupakan salah satu metode optimasi untuk menyelesaikan masalah kuadrat terkecil yang didasarkan pada metode Gauss-Newton[8]. Teknik iterasi untuk meminimalkan fungsi jumlah kuadrat dari nonlinear yang terinterpolasi antara metode Gauss-Newton dan metode Gradient Descent disebut algoritma Levenberg-Marquardt [9].

Kuadrat terkecil nonlinier merupakan bentuk dari analisis kuadrat terkecil yang digunakan untuk melakukan fitting atas sekumpulan pengamatan dengan suatu model nonlinier multivariable. Dalam masalah kuadrat terkecil nonlinier, ditentukan vektor parameter model yang menghasilkan kecocokan paling mungkin antara pengukuran dan prediksi model [8].

Tujuan yang ingin dicapai dalam masalah kuadrat terkecil adalah menentukan peminimal lokal dari [8].

$$
F(x)=\sum_{t=1}^{n}\left(\operatorname{data}(t)-y_{t}(t)\right)^{2}
$$

dimana data merupakan acuan data berdasarkan IHSG, $y_{t}$ merupakan data harga saham yang didapat dari model LPPL. Sedangkan $F(x)$ merupakan fungsi error kuadrat yang diminimumkan.

\section{PERANCANGAN SISTEM}

A. Deskripsi Sistem 
DitTA FEBRIANY SUTRISNA et al.:

Pada penelitian ini, dilakukan perancangan sistem untuk memodelkan prediksi crash harga saham dengan menerapkan model Log Periodic Power Law (LPPL) dengan Nonlinear Optimization. Nonlinear Optimization memerlukan 2 langkah yaitu menggunakan metode Tabu Search dan algoritma Levenberg-Marquardt kuadrat terkecil nonlinier. Keluaran yang diharapkan mendapatkan model yang optimal dan sesuai dengan data acuan berdasarkan data harga saham IHSG. Berikut flowchart untuk penelitian pemodelan prediksi crash harga saham yaitu

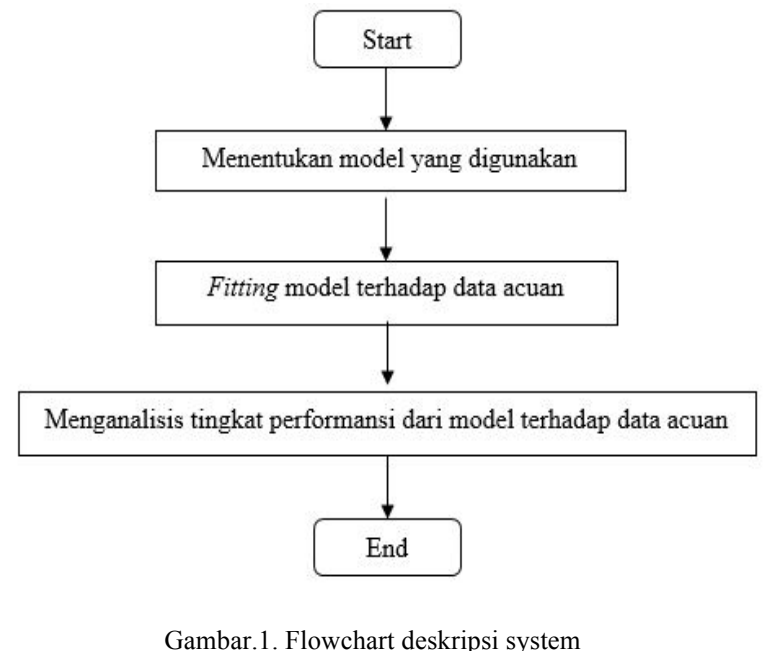

1) Menentukan model yang digunakan

Tahap pertama pada penelitian ini adalah menentukan model yang digunakan. Penentuan model didapat berdasarkan Log Periodic Power Law yang merupakan model harga aset selama gelembung endogen.

2) Fitting model terhadap data acuan

Tahap selanjutnya adalah fitting model terhadap data acuan menggunakan data harga saham IHSG. Fitting model yang digunakan adalah Nonlinear Optimization. Nonlinear Optimization terdapat dua tahap yaitu menggunakan metode Tabu Search dan algoritma Levenberg-Marquardt kuadrat terkecil nonlinier.

3) Menganalisis tingkat performansi dari model terhadap data acuan

Tahap terakhir adalah menganalisis tingkat performansi dari model LPPL terhadap data acuan yang dapat dilihat berdasarkan fitting model dan distribusi $t_{c \text {. }}$

\section{B. Data Acuan}

Data acuan yang digunakan yaitu data harga saham IHSG. Data tersebut dilihat berdasarkan data historis harga saham periode harian sebelum dan sesudah terjadinya crash dari Januari 2006 sampai Desember 2009. Data harga saham yang digunakan yaitu harga penutupan.

\section{Pengujian Dan ANALisis}

\section{A. Harga Penutupan IHSG}

Pada sub bab ini, data IHSG yang digunakan dari 1 Januari 2006 sampai 1 Januari 2009 (observasi 968 hari) seperti gambar dibawah. 


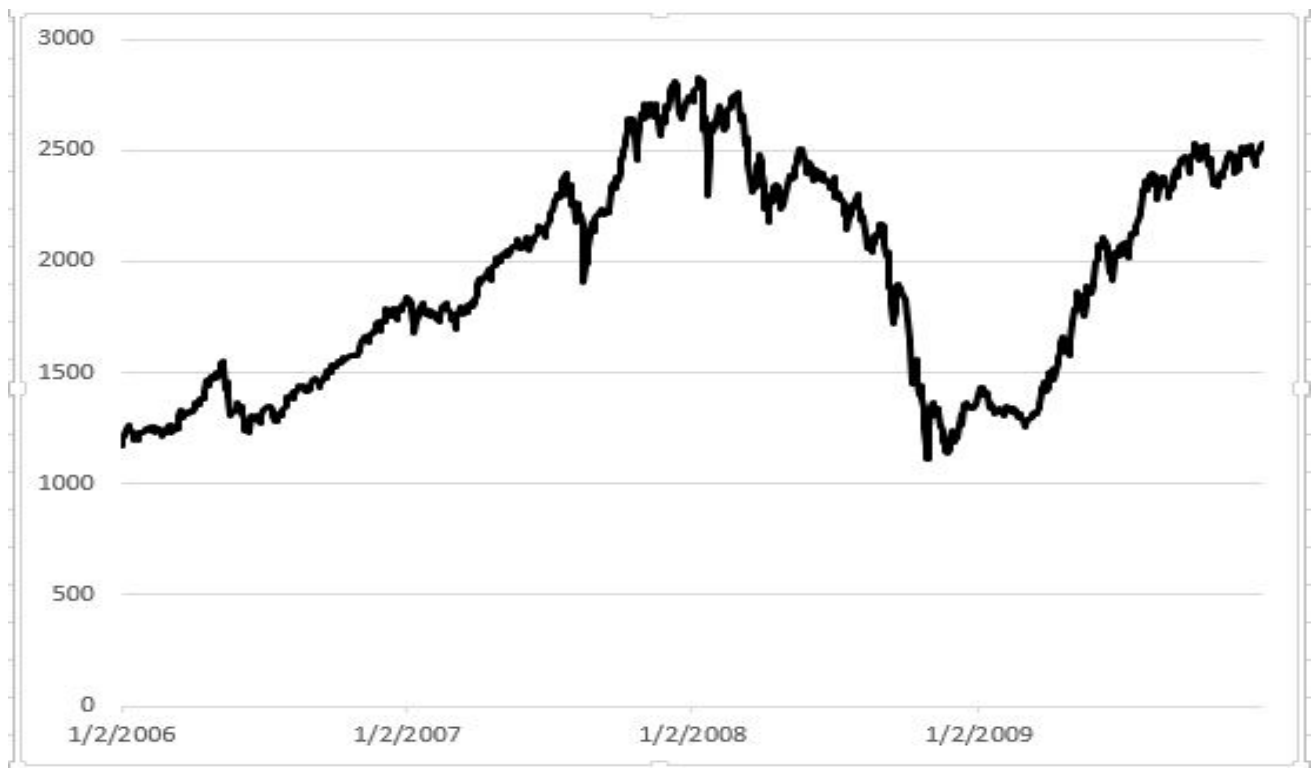

Gambar.2. Harga Penutupan IHSG

Pada penelitian ini, data histori harga saham yang digunakan yaitu sebelum dan sesudah terjadinya crash, dari tahun 2006 sampai 2007 menunjukkan perilaku yang mendekati eksponensial sehingga mencapai data histori maksimum pada tanggal 11 Desember 2007. Diperoleh dari Tabel I, data IHSG dari tahun 2007 sampai 2008, selama bulan Januari dengan return kumulatif harian mencapai sekitar $-2.06 \%$.

TABEL I

RETURN KUMULATIF HARIAN DARI IHSG

\begin{tabular}{|l|l|l|l|}
\hline Bulan & $\begin{array}{l}\text { Return } \\
\text { Kumulatif }\end{array}$ & Bulan & $\begin{array}{l}\text { Keturn } \\
\text { Kumulatif }\end{array}$ \\
\hline Jan-07 & -3.395769483 & Jan-08 & $\mathbf{- 2 . 0 6 0 6 7 7 6 8 7}$ \\
\hline Feb-07 & -0.595701413 & Feb-08 & 0.377531188 \\
\hline Mar-07 & 5.150338979 & Mar-08 & -9.853079092 \\
\hline Apr-07 & 8.031110973 & Apr-08 & -1.724818155 \\
\hline May-07 & 5.456686248 & May-08 & 3.678487509 \\
\hline Jun-07 & 2.706722266 & Jun-08 & -1.955662972 \\
\hline Jul-07 & 4.221576352 & Jul-08 & -5.380980599 \\
\hline Aug-07 & -0.91764058 & Aug-08 & -3.59183016 \\
\hline Sep-07 & 8.181074041 & Sep-08 & $\mathbf{- 2 6 . 0 6 2 2 3 3 2 9}$ \\
\hline Oct-07 & 12.35803429 & Oct-08 & -17.40547801 \\
\hline
\end{tabular}




\begin{tabular}{|l|l|l|l|}
\hline Bulan & $\begin{array}{l}\text { Return } \\
\text { Kumulatif }\end{array}$ & Bulan & $\begin{array}{l}\text { Return } \\
\text { Kumulatif }\end{array}$ \\
\hline Nov-07 & 1.002930828 & Nov-08 & -9.54861601 \\
\hline Dec-07 & 0.267418288 & Dec-08 & 10.91537441 \\
\hline
\end{tabular}

Setelah itu didapatkan pergerakan indeks yang cenderung menurun dari akhir tahun 2007 hingga periode November 2008 dan nilai lokal minimum dicapai pada tanggal 28 Oktober 2008.

\section{B. Hasil Distribusi Waktu Krisis}

Pada skenario ini, untuk mendapatkan distribusi yang sesuai dengan data yang sebenarnya, diperlukan percobaan dengan nilai $k$ yang rendah. Disini penulis menggunakan ukuran jendela puncak $(k)=3$. Dengan nilai $k$ (misalnya, 3 sampai 5) yang rendah, biasanya lebih cocok walaupun sebagian besar nilai puncak tipis [10]. Hasil distribusi waktu krisis dapat dilihat pada gambar dibawah.

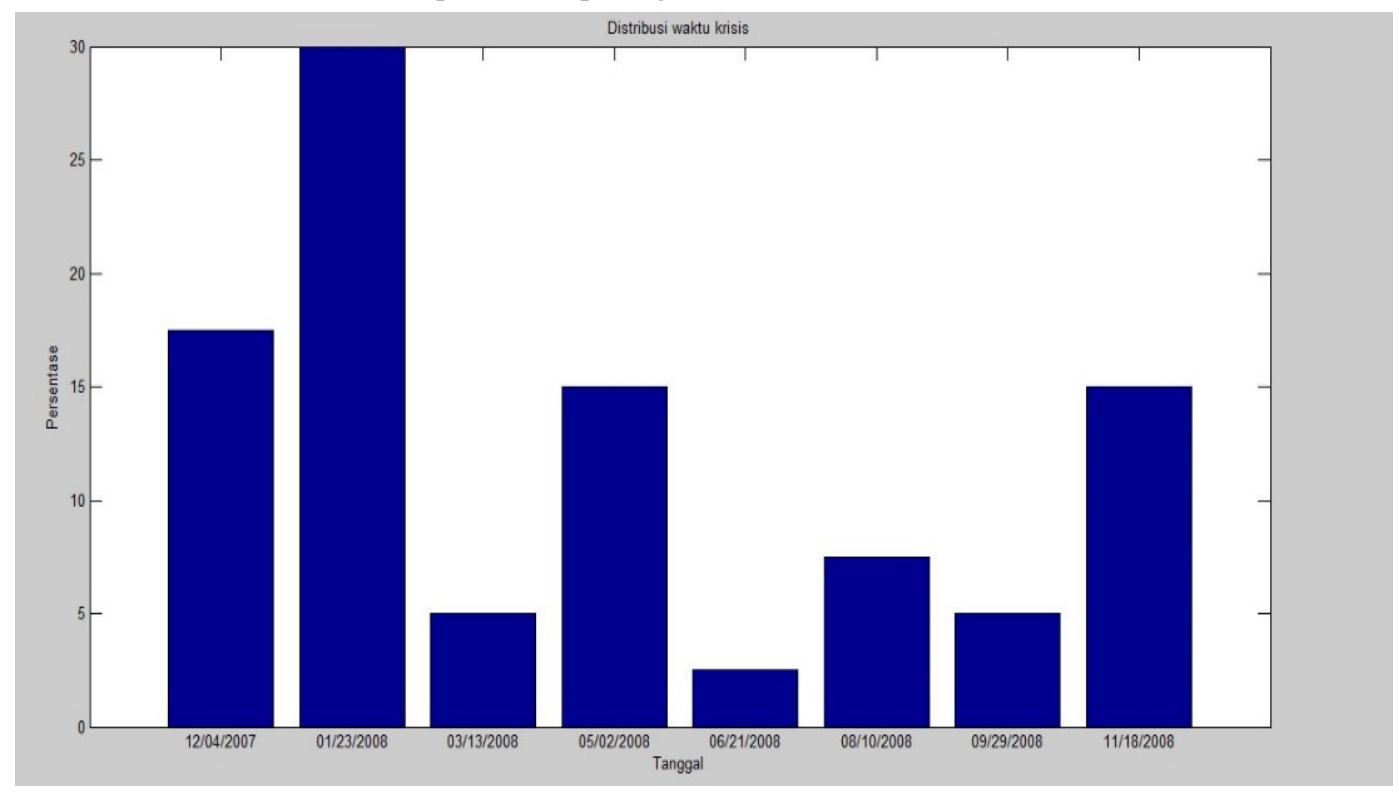

Gambar. 3. Hasil Distribusi Waktu Krisis

Pada gambar. 3. menunjukkan waktu krisis terjadi pada tahun 2007 hingga 2008, dari tanggal 9 November 2007 hingga 11 Desember 2008. Hasil prediksi waktu krisis harga saham dengan model LPPL dan Nonlinear Optimization dapat dilihat dengan peluang paling besar sekitar 23 Januari 2008. Sehingga nilai harapan yang menunjukkan probabilitas waktu paling besar terjadi pada tanggal 31 Januari 2008. Estimasi parameter model LPPL dengan nilai error yang paling kecil sebesar 2.2435e+08, sehingga diperoleh $A=1918.6, B=-0.8543$, $C=0.04, t_{c}=455.5393(9 / 11 / 2007), \beta=0.005, \omega=4.6021$, dan $\varphi=6.9358$.

Krisis yang terjadi di Indonesia dimulai pada akhir tahun 2007 hingga awal 2009, sehingga harga saham di pasar keuangan mulai berjatuhan. Dapat dikatakan bahwa prediksi menggunakan model LPPL dengan metode Nonlinear Optimization mempunyai performansi yang cukup mendekati dengan waktu krisis sebenarnya. 
Lebih tepatnya krisis di Indonesia terjadi sekitar bulan Oktober 2008. Dengan adanya pemodelan crash harga saham diharapkan para investor saham dapat mengambil keputusan lebih berhati-hati saat terjadinya gelembung dan anti gelembung.

\section{Hasil Titik Puncak}

Didapatkan hasil puncak seperti gambar dibawah.

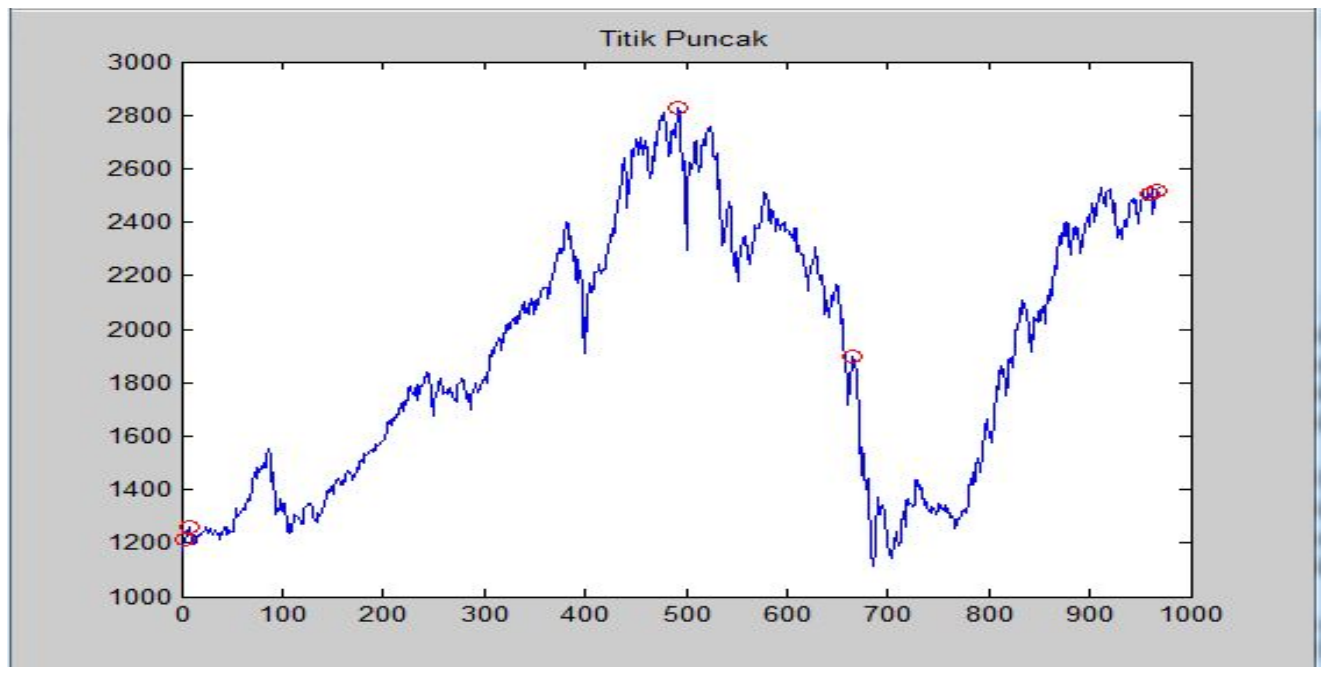

Gambar. 4. Hasil Titik Puncak

Puncak diperoleh dengan nilai harga saham yang paling tinggi diantara harga saham disekitarnya. Dalam mendapatkan nilai-nilai puncak menggunakan dua tahap remove titik puncak. Remove pertama menggunakan batasan nilai $z=9(3 k)$, sedangkan remove kedua menggunakan batasan nilai $k=3 . Z$ adalah ukuran jendela lokal yang membatasi tetangga kiri dan tetangga kanan dari titik harga saham untuk mendapatkan sebuah nilai puncak. Sehingga didapatkan puncak yang paling tinggi atau optimal pada tanggal 9 Januari 2008. Dapat dikatakan bahwa gelembung saham berlangsung sampai titik puncak yang optimal, hingga suatu saat terjadi anti gelembung. Anti gelembung dapat dilihat dari turunnya harga saham secara tiba-tiba pada tahun 2008 yang disebut sebagai crash harga saham.

\section{KESIMPULAN DAN SARAN}

\section{A. Kesimpulan}

Berdasarkan hasil pemodelan yang telah dilakukan, maka dapat disimpulkan bahwa pada proses pencarian crash harga saham, didapatkan hasil pemodelan pada distribusi waktu krisis. Hasil yang diperoleh dari IHSG menunjukan bahwa penggabungan metode antara metode Tabu Search dan algoritma Levenberg-Marquardt kuadrat terkecil nonlinier dapat digunakan untuk memperkirakan waktu terjadinya krisis pada pasar saham. Oleh karena itu, diperoleh waktu krisis dengan nilai harapan yang menunjukkan peluang paling besar pada tanggal 31 Januari 2008, merupakan pendekatan yang sesuai dengan data krisis sebenarnya. 
DitTA FEBRIANY SUTRISNA et al.:

\section{B. Saran}

Setelah proses pemodelan crash harga saham, penulis menemukan beberapa saran yang dapat dilakukan, yaitu :

1. Untuk dapat meningkatkan penelitian, maka diperlukan metode standar yang lebih jelas untuk mengetahui gelembung pasar saham yang sedang berlangsung.

2. Pemodelan crash harga saham ini dapat dibandingkan jika $k$ yang digunakan dapat berbeda.

\section{REFERENSI}

[1] J. Anders, "Testing for financial crashes using the Log Periodic Power Law model”, 2013.

[2] T.P.Daniel, M. Miruna, "Modelling stock market crashes: the case of Bucharest Stock Exchange", Procedia - Social and Behavioral Sciences 58, 2012.

[3] ]T.P. Daniel, "AN LPPL ALGORITHM FOR ESTIMATING THE CRITICAL TIME OF A STOCK MARKET BUBBLE", The 6th International Conference on Applied Statistics, Bucharest, 2012.

[4] D. Valerijonas, S. Leonidas, "THE MATHEMATICAL DEFINITION OF THE BUBBLES AND CRASHES. JAUNUJU MOKSLININKU DARBAI", Nr. 4 (37), 2012.

[5] H.M. Adler, "Bubbles Prices: money market, stock and Properti", SESPIBI, 2012.

[6] Fatmawati, P. Bayu, dkk, "PENYELESAIAN TRAVELLing SALESMAN PROBLEM DENGAN METOdE TABU SEARCH", 2015.

[7] H. Alain, T. Eric, dkk, "A TUTORIAL ON TABU SEARCH. EPFL”, Département de Mathématiques, MA-Ecublens, CH1015 Lausanne.

[8] K.B. Lusia, "METODE LEVENBERG MARQUARDT UNTUK MASALAH KUADRAT TERKECIL NONLINEAR". Prosiding FMIPA Universitas Sanata Dharma Yogyakarta, 2009.

[9] P.G. Henri, "The Levenberg-Marquardt method for nonlinear least squares curve-fitting problems", Department of Civil and Environmental Engineering Duke University, 2015.

[10] K.P. Girish,"Simple Algorithms for Peak Detection in Time-Series”. Tata Research Development and Design Centre (TRDDC). 